\title{
A circuit view of deep brain stimulation in Alzheimer's disease and the possible mechanisms
}

\author{
Danfang $\mathrm{Yu}^{1,2+}$, Huanhuan Yan ${ }^{3,5+}$, Jun Zhou ${ }^{1}$, Xiaodan Yang ${ }^{1}$, Youming $\mathrm{Lu}^{3,4^{*}}$ and Yunyun Han ${ }^{1,4^{*}}$ (D)
}

\begin{abstract}
Alzheimer's disease (AD) is characterized by chronic progressive cognitive deterioration frequently accompanied by psychopathological symptoms, including changes in personality and social isolation, which severely reduce quality of life. Currently, no viable therapies or present-day drugs developed for the treatment of AD symptoms are able to slow or reverse AD progression or prevent the advance of neurodegeneration. As such, non-drug alternatives are currently being tested, including deep brain stimulation (DBS). DBS is an established therapy for several neurological and psychiatric indications, such as movement disorders. Studies assessing DBS for other disorders have also found improvements in cognitive function, providing the impetus for clinical trials on DBS for AD. Targets of DBS in AD clinical trials and animal model studies include the fornix, entorhinal cortex (EC), nucleus basalis of Meynert (NBM), and vertical limb of diagonal band (VDB). However, there is still no comprehensive theory explaining the effects of DBS on AD symptoms or a consensus on which targets provide optimal benefits. This article reviews the anatomy of memory circuits related to $A D$, as well as studies on DBS rescue of $A D$ in these circuits and the possible therapeutic mechanisms.
\end{abstract}

Keywords: Alzheimer's disease, Deep brain stimulation, Fornix, Entorhinal cortex, Nucleus basalis of Meynert, Vertical limb of diagonal band

\section{Background}

Alzheimer's disease (AD) represents a considerable health threat as increases in life expectancy elevate the incidence of $\mathrm{AD}$ worldwide [1]. It is characterized by cognitive decline, alterations in synaptic transmission, and neuronal death brought on by the accumulation of neurofibrillary tangles in neurons and neuritic amyloid beta $(\mathrm{A} \beta)$ plaque in the brain parenchyma [2]. Currently, there is no viable therapy to slow or reverse AD progression. Furthermore, no present-day drugs developed for the treatment of $\mathrm{AD}$ symptoms can prevent the underlying progression of neurodegeneration [3]. Therefore, several non-pharmaceutical approaches are currently being tested [4], including deep brain stimulation (DBS) [5].

\footnotetext{
* Correspondence: lym@hust.edu.cn; yhan@hust.edu.cn

${ }^{\dagger}$ Danfang Yu and Huanhuan Yan contributed equally to this work.

${ }^{3}$ Department of Physiology, School of Basic Medicine and Tongji Medical College, Huazhong University of Science and Technology, Wuhan, China 'Department of Neurobiology, School of Basic Medicine and Tongji Medical College, Huazhong University of Science and Technology, Wuhan, China Full list of author information is available at the end of the article
}

As an established therapy for the treatment of medically refractory movement disorders, such as Parkinson's disease [6], essential tremor [7], and dystonia [8], the benefits of DBS are well documented. The minimal invasiveness and relatively low levels of serious complications have also led to its application in other neurological and psychiatric disorders, such as depression [9], obsessive-compulsive disorder [10], Tourette syndrome [11], obesity [12], and chronic pain [13].

The initiation of clinical DBS trials in AD came from the fortuitous discovery of cognitive improvements in patients undergoing DBS for other diseases, including obesity [14] and Parkinson's disease [15]. Such studies also highlighted potential experimental target areas, with common DBS targets for AD treatment found to include the fornix [5], entorhinal cortex (EC) [16], nucleus basalis of Meynert (NBM) [17], vertical limb of diagonal band (VDB) [18], and ventral capsule/ventral striatum [19]. However, it remains uncertain which of these targets is most effective or how chronic stimulation impacts neurocellular and circuit function. Given the 
multiplicity of effective stimulation targets, the question naturally arises as to whether their therapeutic mechanisms are similar. In other words, it is unclear if the compensatory network processes enabled by DBS are similar or unique for each target. This issue is critical for effectively targeting different AD symptoms and pathogenic mechanisms. This article anatomy of memory circuits related to AD, as well as studies on DBS rescue of $\mathrm{AD}$ in these circuits and the possible therapeutic mechanisms, with particular emphasis on the medial temporal lobe (fornix and EC) and basal forebrain (BF) cholinergic system (NBM and VDB).

\section{Main text \\ Relationship between memory circuitry and AD Medial temporal lobe}

The first reported symptoms of AD are difficulty in remembering new information and episodic memory loss [20], which are hippocampus dependent [21]. Hippocampal atrophy is widely observed in the majority of $\mathrm{AD}$ patients and is considered a characteristic physiological feature associated with cognitive deficits. Indeed, hippocampal atrophy imaging is a valuable tool for assessing disease stage and has provided multiple clues to the mechanisms underlying the behavioral manifestations of AD [22]. The first comprehensive hierarchical staging of $\mathrm{AD}$ by neuropathological examination revealed that the accumulation of neurofibrillary tangles occurs initially in the EC and then spreads to all isocortical association areas, including the hippocampal formation [23]. Consistent with the neuropathological literature, the presence of elevated neocortical (18) F-T807 (a Tau protein binding molecule that can be detected by positron emission tomography (PET)), particularly in the inferior temporal gyrus, is associated with clinical impairment [24].

As part of the Papez circuit, the fornices are thought to contribute to the efficient encoding and normal recall of new episodic information [25]. Indeed, forniceal lesions produce severe memory impairments [26]. Quantitative fiber tracking has demonstrated an age-dependent reduction in forniceal integrity during healthy aging [27] and atrophy of the fornix and mammillary body (MB) can accompany the change from mild cognitive impairment to clinical AD [28]. A significant reduction in fractional anisotropy, which is indicative of reduced white matter tract integrity, is also found to precede forniceal volume loss in patients with genetically inherited dementia, as measured by diffusion tensor imaging [29].

\section{Basal forebrain cholinergic system}

Since 1906, when Alois Alzheimer first delineated the symptomatology of the disease that bears his name, many have tested the hypothesis that degeneration or dysfunction of BF cholinergic circuitry is responsible for the cognitive impairments associated with $\mathrm{AD}$ [30]. The first evidence for network dysfunction in $\mathrm{AD}$ was the NBM cholinergic neuronal loss found in postmortem brains [31]. These findings provided the foundation of the cholinergic hypothesis, which states that the loss of cholinergic neurons is a seminal event leading to $\mathrm{AD}$ [30]. Identification of neurofibrillary tangle formation and degeneration of NBM cholinergic neurons supports the cholinergic hypothesis [32]. Indeed, there is a strong correlation between $\mathrm{BF}$ cholinergic neuron survival and AD onset and severity [18, 33, 34]. BF neurons, specifically those in the NBM, selectively degenerate in AD [35]. Severe deficits in the cholinergic VDB-hippocampal projection system are also found in $\mathrm{AD}$ [36], in agreement with our finding that cholinergic fiber lesions appear earlier than cholinergic neuronal loss in AD model mice [34]. In AD mice, direct cholinergic synaptic transmission from the VDB to hippocampus is impaired, which contributes to the loss of pattern separation-dependent spatial memory [18].

\section{Anatomy of memory circuitry Medial temporal lobe}

Major subdivisions of the medial temporal lobe cortex include the hippocampal formation and parahippocampal gyrus (Fig. 1) [37, 38]. The hippocampus can be described more holistically as a curved and recurved sheet of cortex that is folded onto the medial surface of the temporal lobe. The EC, located anteriorly in the parahippocampal gyrus, is the major input structure to the hippocampus, whereas the fornix is the major output structure.

The EC is divided into the medial EC (MEC) and lateral EC (LEC) based on distinctive cytoarchitecture and connectivity patterns [38]. The MEC contains strongly position-related (spatial) neurons [38-40], whereas the LEC contains neurons encoding object information, attention, and motivation [38, 40, 41]. The afferents from the EC to hippocampus are divided into the perforant and temporoammonic paths, also known as the indirect and direct paths, respectively, referring to their relay connections to the CA1 [21, 42] (see Fig. 1d). Axons from the LEC form the lateral perforant path, whereas those from the MEC form the medial perforant path to the hippocampus [43]. LEC projection neurons selectively form direct excitatory synapses onto a subpopulation of calbindin-expressing pyramidal neurons in the CA1, whereas MEC neurons uniformly innervate all CA1 pyramidal neurons [44].

The fornix (Fig. 1c) is a white matter tract running through the medial aspect of the cerebral hemispheres $[45,46]$. The fornix is a bilateral structure with rich connections between both hemispheres. At the level of the foramen of Monro and anterior commissure, the body of 


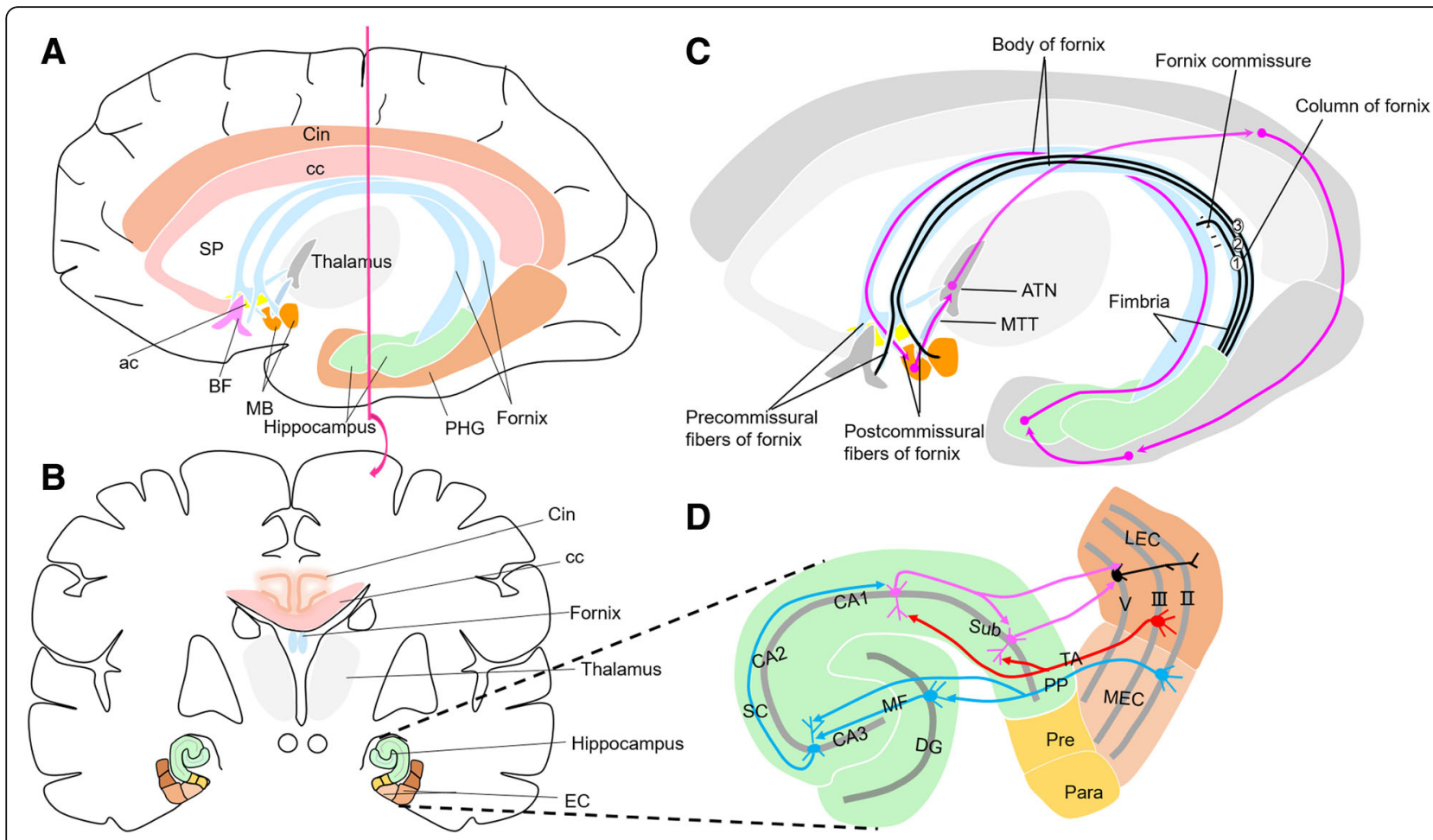

Fig. 1 a Lateral-medial view showing location of the hippocampus and parahippocampus gyrus (PHG) in the temporal lobe. b Brain is sectioned coronally to show the hippocampus and entorhinal cortex (EC) of the medial temporal lobe. $\mathbf{c}$ Anatomy of the fornix and Papez circuit. Black lines show columns of the fornix. Column 1 = fibers crossing the hippocampal commissure to join the contralateral forniceal body. Column $2=$ postcommissural fibers of the fornix that arise primarily from the subiculum and project to the mammillary body. Column 3 = precommissural fibers of the fornix that arise from the pyramidal cell layer of the hippocampus and project to the BF. Magenta lines indicate path of Papez circuit (hippocampus-fornix-MB-MTT-ATN-Cin-EC-hippocampus) and dots indicate integration sites. d Anatomy of EC-hippocampus network. Partial magnification of Fig. $1 \mathrm{~b}$ with a $90^{\circ}$ counterclockwise rotation. EC and hippocampus form a principally unidirectional network, with input from the EC. PP consists of axons from EC layer II stellate cells, projecting indirectly to the hippocampal CA1 area via Mossy fibers from the DG and Schaffer collaterals from the CA3 (red lines). TA consists of axons from EC layer III pyramidal cells, projecting directly to hippocampal CA1 (blue lines). Neurons from CA1 and subiculum (Sub), in turn, send the main hippocampal output back to the EC layer V (magenta lines), forming a loop. Abbreviations: ac, anterior commissure; ATN, anterior thalamic nuclei; BF, basal forebrain; cc, corpus callosum; Cin, cingulate gyrus; DG, dentate gyrus; EC, entorhinal cortex; LEC, lateral entorhinal cortex; MB, mammillary body; MEC, medial entorhinal cortex; MF, Mossy fibers; MTT, mammillothalamic tract; Para, parasubiculum; PHG, parahippocampal gyrus; PP, perforant path; Pre, presubiculum; Sub, subiculum; SC, Schaffer collateral; SP, septa pellucidum; TA, temporoammonic path

the fornix splits in a way that reflects the areas of origin in the hippocampus. The fibers passing in front of the anterior commissure (precommissural fibers) are those originating from the pyramidal cell layer of the hippocampus (along with fibers from the EC and subiculum). The fibers passing behind the commissure (postcommissural fibers) arise from the subiculum of the hippocampus.

The precommissural fibers extend down the columns of the fornix to terminate in the BF (including the septum), ventral striatum, and prefrontal cortex. They also contain substantial projections from the septum and VDB to the hippocampus. The postcommissural fibers extend down the columns to the thalamus and hypothalamus. About one half to two thirds of these fibers directly innervate the anterior thalamic nucleus of the thalamus, with the remaining fibers descending to innervate the $\mathrm{MB}$ of the hypothalamus, among other regions.
First described by James Papez [47], the classic Papez circuit contains most of the medial temporal lobe, including the hippocampus, EC, and fornix (Fig. 1c). Some fibers of the fornix originate from the hippocampus and terminate in the MB. Fibers from the MB pass backward into the anterior thalamic nucleus via the mammillothalamic tract (MTT) and then onto the cingulum. The cingulum is connected to association cortices and the hippocampus, thus completing the Papez loop.

\section{Basal forebrain cholinergic system}

Most cholinergic neurons in the mammalian brain are found in four regions [34, 48, 49]: i.e., brainstem nuclei, subset of thalamic nuclei, striatum, and BF nuclei. We reconstructed a 3D image stack of cholinergic neurons in the entire left hemisphere of a mouse brain by choline acetyltransferase staining (Fig. 2) [34]. 


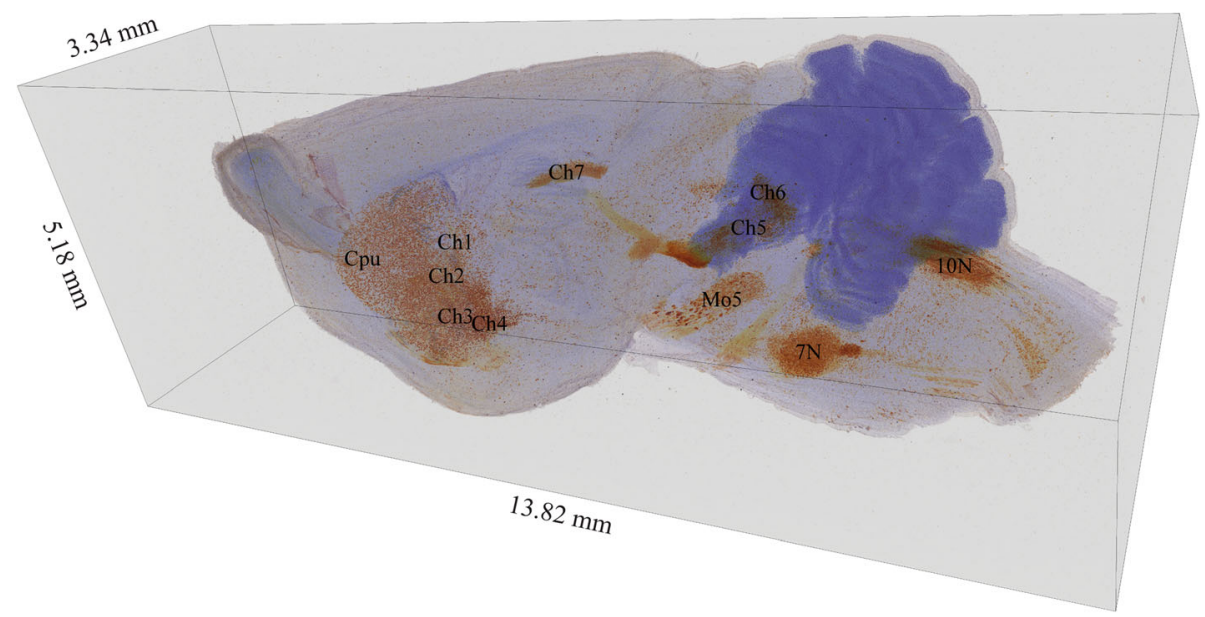

Fig. 2 3D reconstructed image of cholinergic neuron distribution in the left hemisphere of the brain. In primates, cholinergic neurons are assigned to eight groups: Ch1 = medial septal (MS), Ch2 = vertical limb of the diagonal band of Broca (NDB), Ch3 = horizontal limb of the diagonal band of Broca (HDB), Ch4 = nucleus basalis of Meynert (NBM), Ch5 = pedunculopontine nucleus (PPN), Ch6 = laterodorsal tegmental complex (LDT), Ch7 = medial habenula (MH), Ch8 = parabigeminal nucleus (PBN). In this figure, Ch1-7 correspond to related cholinergic neuron groups in the mouse brain. Cpu = caudate putamen, Mo5 = motor trigeminal nucleus, $7 \mathrm{~N}=$ facial motor nucleus, $10 \mathrm{~N}=$ dorsal motor nucleus of vagus

The BF contains at least three distinct populations of neurons (i.e., cholinergic, glutamatergic, and GABAergic) across its different regions. Cholinergic neurons of the BF are located in clusters from the olfactory tubercle to the rostral end of the lateral geniculate bodies. At the anterior pole of the $\mathrm{BF}$, cholinergic neurons are located in the medial septal (MS) and diagonal band, which consists of a horizontal limb (HDB) and a vertical limb (VDB).

At the posterior pole of the $\mathrm{BF}$, cholinergic neurons are found in the NBM [48]. There are striking interspecies differences in the anatomy of the NBM. According to comparative anatomical studies, the NBM in rodents is rudimentary and considerably interdigitated with the globus pallidus, whereas in non-human primates and humans the nucleus exhibits substantial development in size and differentiation from surrounding cell groups [50].

The anterior section of the NBM is limited inferiorly by the HDB, superomedially by the ventral globus pallidus, and superolaterally by the lateral extension of the anterior commissure [51]. The posterior section abuts the ansa lenticularis superiorly, the putamen laterally, the posterior tip of the amygdala inferiorly, and the optic tract medially [51] (Fig. 3).

The VDB is located along the ventromedial border of the septum. It contains the greatest number of hyperchromic fusiform neurons in the entire septal area [52]. These VDB cholinergic neurons merge with the MS cell group dorsally and with the HDB and NBM groups ventrally [52].

These BF cholinergic projection neurons send extensive, multi-branched inputs to the neocortex, archicortex (e.g., hippocampus), and other subcortical structures [52, 53]. New tracing technologies have revealed that individual cholinergic neurons can project to distinct distal brain regions via different projection routes and that adjacent $\mathrm{BF}$ neurons can have highly diverse projection patterns [49]. The NBM constitutes the single largest source of cholinergic innervation to the entire cortical surface (Fig. 3), whereas the VDB is the major source of cholinergic innervation to the hippocampus from the basal cholinergic nuclei $[52,54]$ (Fig. 4). The CA1 pyramidal neurons and dentate gyrus (DG) in the dorsal hippocampus receive afferent cholinergic inputs almost exclusively from the VDB, whereas the corresponding cell layers in the ventral hippocampus are supplied by both the VDB and MS [55] (Fig. 4). The VDB projects to the hippocampus via the fornix and fimbria [56] and can directly innervate newly generated immature neurons in the DG of adult mice [18].

Retrograde tracing studies have shown that different $\mathrm{BF}$ subregions receive diverse inputs from multiple olfactory cortices [57]. Cholinergic neurons in the medial and caudal HDB and VDB receive inputs from the entire olfactory system, including the olfactory bulb, anterior olfactory nucleus, EC, basolateral amygdala, and especially the piriform cortex and hippocampus; whereas, the MS and part of the rostral HDB receive inputs predominantly from the hippocampus and the NBM receives inputs mainly from the central amygdala [57]. NBM neurons also receive other cortical input from the orbitofrontal cortex, anterior insula, temporal pole, entorhinal cortex, and medial temporal cortex [58], although most sensory, motor, and association areas in the frontal, parietal, occipital, and temporal lobes do not project to the NBM [58]. There are also subcortical inputs to the NBM from the septal nuclei, nucleus accumbens-ventral pallidum complex, and hypothalamus [58]. These 


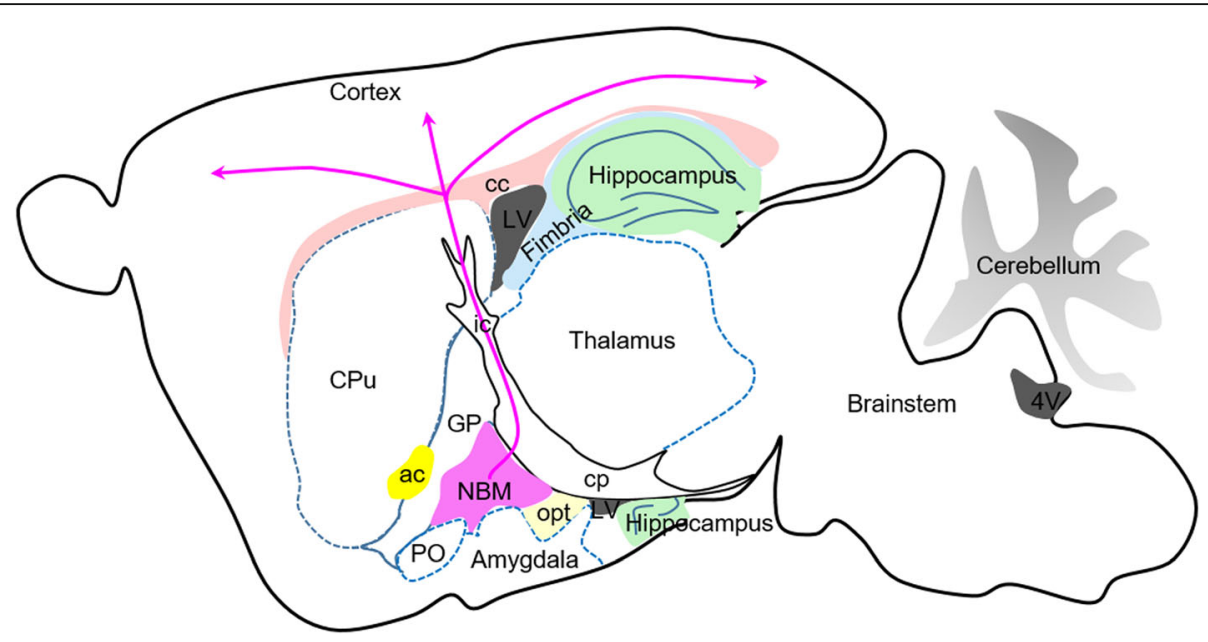

Fig. 3 Sagittal schematic of NBM cell body location and projections in mice. NBM is extensive and has close topographical relationships with many different structures. Consistently, the NBM is always adjacent to the globus pallidus (GP) and is the main cholinergic projection to the neocortex and amygdala. Connectivity between individual sectors of the NBM and various cortical areas displays topographic specificity. Abbreviations: ac, anterior commissure; cc, corpus callosum; $\mathrm{cp}$, cerebral peduncle; CPu, caudate putamen; GP, globus pallidus; ic, internal capsule; $\mathrm{LV}$, lateral ventricle; opt, optic tract; PO, preoptic area

synaptic inputs to the NBM consist of cholinergic, catecholaminergic, and $\gamma$-aminobutyric acid axons [59].

\section{Results of human DBS in memory circuitry for AD Clinical trials of DBS in the medial temporal lobe}

The potential of fornix-DBS (f-DBS) for memory improvement was first suggested by a case study reporting activation of autobiographical memories and improvement in verbal and visuospatial memories in a patient who underwent DBS for obesity [14]. To localize the stimulation site responsible for these changes, stereotactic coordinates of the active DBS contacts were determined from postoperative images. These coordinates were then plotted onto the Schaltenbrand-Wahren brain

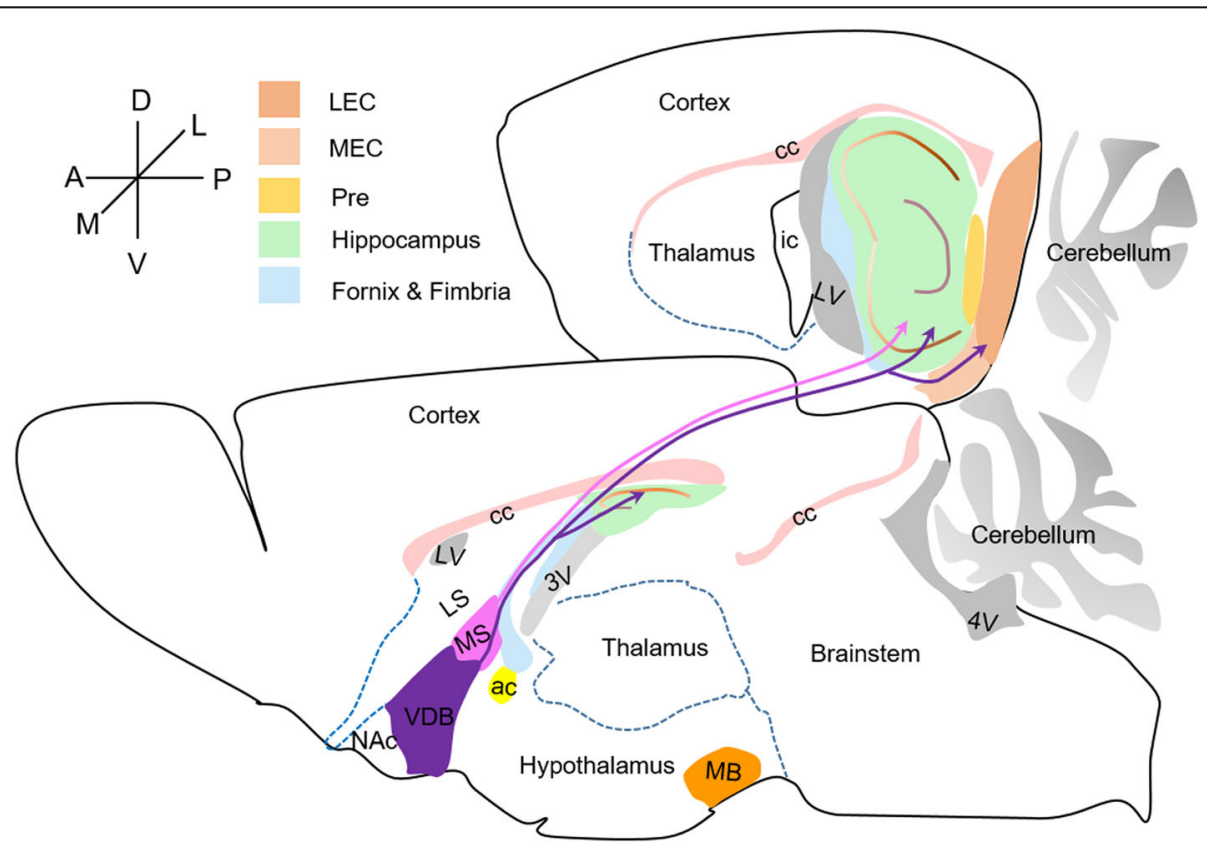

Fig. 4 Sagittal schematic of locations and projections of MS and VDB in mice. The MS is located in the middle of the septum and many neurons are embedded among the precommissural fibers of the fornix. The VDB is located below the MS along the ventromedial and dorsomedial borders of the LS. The VDB projects via the fornix and fimbria to both the dorsal and ventral hippocampus formation, whereas the MS projects only to the ventral hippocampus. Abbreviations: ac, anterior commissure; cc, corpus callosum; ic, internal capsule; LEC, lateral entorhinal; LS, lateral septum; LV, lateral ventricle; MB, mammillary body; MEC, medial entorhinal; MS, medial septum; NAc, nucleus accumbens; Pre, presubiculum 
atlas and estimated to be adjacent to the columns of the fornix [60]. This discovery led to a phase I clinical trial consisting of six patients with early stage AD (ClinicalTrials.gov Identifier: NCT00658125) [61]. During implantation surgery, two subjects reported stimulationinduced autobiographical experiential phenomena. Memory improvements were also reported in some participants after 12 months of DBS, especially in those who experienced vivid experiential phenomena during surgery and had less severe memory problems at baseline [61]. Functional connectivity analyses also revealed that 1 year of f-DBS treatment increased cerebral glucose metabolism in two orthogonal networks: i.e., the frontaltemporal-parietal-striatal-thalamic network and frontaltemporal-parietal-occipital-hippocampal network [62]. Higher baseline metabolism in similar cortical regions prior to DBS and increased metabolism in similar regions after 1 year of DBS were correlated with better outcomes in global cognition, memory, and quality of life [62]. Among the six patients, bilateral hippocampal volume increases were observed in the two patients with the best clinical response, with one of these patients exhibiting preserved hippocampal volume 3 years after diagnosis [63]. In contrast, none of the matched control AD patients, who received only ongoing medication, demonstrated bilateral hippocampal enlargement [63]. This study demonstrates that in addition to modulating neural circuit activity, DBS can influence the natural course of brain atrophy in a neurodegenerative disease. Based on these phase I trial results, a randomized, double-blind, placebo-controlled, delayed-start phase II clinical trial (ADvance trial) was conducted at multiple North American institutions (ClinicalTrials.gov Identifier: NCT01608061) [64]. Across surgeons and treatment centers, the ADvance research group reported that it was feasible to accurately target DBS to the fornix without direct injury [64]. Bilateral f-DBS was also well tolerated by patients with mild probable AD at 90 days after surgery [64]. At 12 months after electrode implantation, the ADvance research group evaluated active "on" versus sham "off" bilateral DBS directed at the fornix in 42 patients with mild $\mathrm{AD}$ and found increased cerebral glucose metabolism without adverse effects [64]. Recently, although the ADvance research group reported no differences in cognitive outcomes among participants as a whole, participants aged $\geq 65$ years appear to have benefited from DBS, whereas patients aged $<65$ years appear to have worsened [65]. The ADvance trial is still active but not recruiting, so the influence of f-DBS on different AD stages is still unclear.

In 1934, Penfield first reported that an epileptic patient subjected to low intensity electrical stimulation to specific regions of the cortex during awake neurosurgery "re-lived" an event from his/her past; between the 1930s and 1960s, Penfield further reported 40 similar cases [66]. Since this pioneering work, other studies have also described experiential phenomena after electrical stimulation $[67,68]$. Such findings are the major inspiration for preliminary trials aimed at improving memory performance using electrical stimulation in the EC. A group from the University of California implanted intracranial depth electrodes in seven subjects to identify seizure onset zones for subsequent epilepsy surgery and found that stimulation of the EC enhanced memory of spatial information applied during learning [67].

\section{Clinical trials of DBS in the basal forebrain}

Among the earliest targets for electrical stimulation in AD was the NBM. In 1984, attempting to augment the remaining tonic cholinergic inputs to the cortex and increase associated cortical metabolic activities, Turnbull et al. implanted DBS electrodes into the left NBM of a 74-year-old man with probable AD. After 8 months stimulation, the authors reported no clinically significant response, although they did not use detailed neuropsychological assessments with standardized measures [69]. Improvement in cognitive function by NBM-DBS was first demonstrated in a patient with slowly progressive Parkinson-dementia syndrome implanted with two NBM electrodes in addition to electrodes in the subthalamic nucleus [15]. This discovery led to a phase I clinical trial recruiting six patients with light to moderate AD (ClinicalTrials.gov Identifier: NCT01094145). Considering all limitations of this pilot study, DBS of the NBM was both technically feasible and well tolerated [70]. Patients who were less affected before treatment were less likely to deteriorate during chronic DBS [70]. Based on this observation, they performed NBM-DBS on two younger patients with milder AD [71] and found that changes in vitamin B12 compared to baseline levels following NBM-DBS were associated with cognitive status [72]. Furthermore, Alzheimer's Disease Assessment Scale scores assessed over 24 months showed that NBMDBS performed at an earlier stage of the disease and at a younger age may have a favorable impact on disease progression and cognitive function [73].

\section{Possible therapeutic mechanisms of DBS in memory circuitry}

One possible therapeutic mechanism of DBS in the memory circuits is diminished synaptic loss. Surgical lesions of the descending postcommissural fornix or complete fornix both result in $\mathrm{MB}$ shrinkage without $\mathrm{MB}$ neuronal loss $[74,75]$. We found that EC-DBS could rescue synaptic defects of the EC layer II to CA1 that were selectively degenerated in AD mice [76]. Tonegawa et al. found that optogenetic induction of long-term potentiation of the perforant path restored spine density 
from EC synapses to the $\mathrm{DG}$ in $\mathrm{AD}$ mice [77]. In addition, VDB-DBS has been shown to rescue the reduction in cholinergic synapse density in the DG [18]. These results indicate that diminished synaptic loss is feasible following DBS treatment.

Secondly, DBS in the memory circuits may also induce neurogenesis. Neurogenesis continuously occurs throughout life in the subventricular zone and granule cell layer of the DG. Adult-generated DG cells are thought to contribute to the formation of hippocampus-dependent memories [78]. The precommissural fornix contains cholinergic fibers innervating the DG [56], which can increase the survival of newly generated immature neurons in the DG [79, 80]. A study on the effects of 4-h acute stimulation to the fornix found no evidence for induced neurogenesis based on similar numbers of BrdU/NeuN double-labeled cells in the DG of both f-DBS and sham groups [81]. However, we observed prolonged lifespan for newly generated immature neurons without an increase in the total number of BrdU-labeled neurons when cholinergic fibers were stimulated [18]. Lozano and Frankland also reported that ECDBS can influence cognitive function via activitydependent regulation of hippocampal neurogenesis in $A D$ mice [68].

Thirdly, DBS in the memory circuits may also enhance cerebral glucose metabolism. Glucose is the obligatory physiological energy substrate of the brain [82], and regional reductions in glucose utilization in the temporal lobe and posterior cingulate area are common features in early $\mathrm{AD}$, as revealed by PET and single photon emission computed tomography [83, 84]. Numerous studies have indicated that neurons are inherently capable of activityinduced glucose uptake and glycolytic processing [85-87]. Widespread increases in glucose consumption are found during and immediately after neuronal activation [88, 89]. Many studies examining brain metabolism by blood oxygenation level-dependent (BOLD) fMRI or cerebral blood flow by PET have indicated a close relationship between DBS and its global neuromodulatory effects [90, 91]. For example, the increased metabolism observed in two orthogonal networks after 1 year of f-DBS was correlated with better outcomes in global cognition, memory, and quality of life [62]. Furthermore, electrical stimulation of the perforant path with continuous high-frequency $(100 \mathrm{~Hz})$ pulses generated BOLD responses in the hippocampus formation and in various target regions, i.e., medial prefrontal cortex, nucleus accumbens, and ventral tegmental area/substantia nigra region $[92,93]$. In the earliest NBM-DBS case, increased cortical glucose metabolism was detected by fluorodeoxyglucose (FDG)-PET studies [27]. A subsequent phase I NBM-DBS trial using FDG-PET found a global increase of $2-5 \%$ in cortical glucose metabolism in three of four patients, which was most pronounced in the amygdala, hippocampal, and temporal regions [55].
Fourthly, DBS in the memory circuits may also drive interactions between medial and corticolimbic circuits, leading to a release of various neurotransmitters. Previous research has reported that $\mathrm{f}$-DBS can activate the hippocampus and induce the release of acetylcholine (ACh) in this region [94] due to stimulation of the precommissural fibers (Fig. 1c), which primarily consist of cholinergic axons from the nucleus of the diagonal band that innervate the hippocampus [95]. For NBM-DBS, low-frequency stimulation $(20 \mathrm{~Hz})$ in rats [70], which resembles the physiological discharge rate of NBM neurons during motor activity in freely moving animals [96], activated ACh release from cortical terminals originating in the NBM [97]. Intermittent NBM stimulation can also improve working memory in adult monkeys by increasing cholinergic transmission, with the effect abrogated by either nicotinic or muscarinic cholinergic receptor antagonists [98]. In addition, f-DBS can also drive dopaminergic and glutamatergic transmission in anesthetized swine through the nucleus accumbens [99]. Postcommissural fibers of the fornix (Fig. 1c), including subiculum to MB projections, can regulate stress hormones following memory retrieval [100]. Understanding the exact identity of these transmitters and their sources is critical for clarifying the therapeutic effects of DBS. For example, degeneration of dopaminergic neurons at pre-A $\beta$-plaque stages contributes to memory deficits and dysfunction in reward processing [101]. A subset of nucleus accumbens medium spiny neurons receive inputs from the ventral hippocampus via the fornix, the activation of which increases the number of spontaneously active dopamine neurons in the ventral tegmental area [102]. Chronic stimulation of f-DBS may result in continuous activation of dopamine neurons in the ventral tegmental area; however, continued activation of dopamine neurons by DBS impairs verbal memory persistently across long periods of time [103]. Therefore, more direct evidence is needed to illustrate the exact relationship between its therapeutic effects and the transmitters or hormones released by DBS.

Fifthly, DBS in the memory circuits may also reduce $A \beta$ plaque load of the projecting targets of the DBS site. Although the $\mathrm{A} \beta$ hypothesis of $\mathrm{AD}$ remains unproven, it largely remains defined by the central tenet that accumulation of $A \beta$, in a variety of forms, triggers a cascade that harms neurons and synapses [2]. In young AD transgenic mice, EC-DBS is reported to reduce $A \beta$ plaque load in the dorsal hippocampus, prefrontal cortex, and amygdala [16]. These areas are all direct projection targets of the EC. In contrast, however, EC-DBS did not reduce $\mathrm{A} \beta$ plaque load in six-month-old $\mathrm{AD}$ mice, despite successful rescue in memory deficits [16]. This suggests that DBS may act through $A \beta$ plaque-dependent mechanism only in early stage $\mathrm{AD}$. Alternatively, $\mathrm{A} \beta$ plaque load reduction may not be the primary mechanism by which DBS reverses memory deficits. This is consistent with a number of observations 
including: 1) before $A \beta$ plaque deposition, amnesia in $A D$ mice is age-dependent [104-106]; (2) similar dissociations between memory loss and $A \beta$ plaque load have been reported in AD patients [107]; and (3) immunotherapy against $A \beta$ rescues memory deficits in $A D$ mouse models without affecting $A \beta$ plaque load [108].

Lastly, DBS in the memory circuits may also selectively stimulate M1 Ach receptors. Drugs that promote cholinergic signaling by blocking enzymatic degradation of ACh account for $75 \%$ of FDA-approved treatments for $\mathrm{AD}$ and these cholinesterase inhibitors have been shown to improve cognition in mild-to-moderate $\mathrm{AD}$ patients [109]. Metabotropic cholinergic responses are mediated by the five muscarinic ACh receptors subtypes (M1M5). The distribution of these receptors alters with aging and progress of $\mathrm{AD}$ [110]. The localization of specific muscarinic ACh receptor subtypes in the hippocampus, and the brain in general, largely comes from the early work of Levey and colleagues [111, 112]. M1 ACh receptor expression is high throughout the hippocampus, particularly in the DG, and exhibits graded expression across the CA subfields, increasing from CA3 to $\mathrm{CA} 1$ and the subiculum. The M1 ACh receptor plays a crucial role in learning and memory and is closely associated with $\mathrm{AD}$, and thus has long been postulated as a therapeutic target. Pharmacological stimulation of M1 ACh receptors exhibits advantages for cognitive improvement in $\mathrm{AD}$ patients $[113,114]$; to date, however, no M1 ACh receptor agonist has been approved by the US FDA due to adverse side-effects. VDB-DBS may mimic the therapeutic effects of M1 Ach receptors in the DG but avoid the side-effects of general administration of M1 ACh receptor agonists.

\section{Conclusions}

Early hypotheses on DBS mechanisms were obtained from studies on movement disorders, proposing that stimulation inhibited neuronal activity at the site of stimulation, thereby imitating the effects of surgical ablation. Subsequent studies have challenged this view, instead suggesting that high frequency stimulation increases and synchronizes output from the stimulation site by directly activating axons of local projection neurons, even if somatic activity near the DBS electrode is suppressed [115]. However, fundamental questions remain about the effects of DBS on the neurons surrounding the electrode and on their larger scale consequences. In AD DBS studies, increased glucose metabolism, neurotransmitter release, and neurogenesis suggest an activating effect of DBS at the neurocircuitry level.

Recent studies have also revealed network level effects of DBS. It appears that the stimulation targets that improve memory primarily function at the network level in order to coordinate activities among multiple brain regions. It is thought that different brain areas are involved in distinct stages of memory, with the hippocampus, especially the DG, essential for memory formation and the initiation of memory consolidation [116]. The earliest symptom of $\mathrm{AD}$ is anterograde amnesia, and the earliest pathological changes are observed in the EC and hippocampus. Therefore, DBS targets that directly rescue EC and hippocampal neurons may be most effective for slowing $\mathrm{AD}$ progression. However, the most intensively studied DBS targets in AD patients are the fornix and NBM based on serendipitous findings rather than knowledge of $\mathrm{AD}$ pathological mechanisms. These DBS targets appear to be related to memory retrieval [100] or fast modulation of conveyed cognitive information [117], rather than memory formation and consolidation. Moreover, these stimulation targets are chosen by different study groups based on the best outcome according to their own working hypotheses. For memory improvement induced by DBS, however, it is crucial that we determine whether these DBS sites have selective effects on specific types of memory and which locations are preferable for improving each. Several research groups have realized the above-mentioned
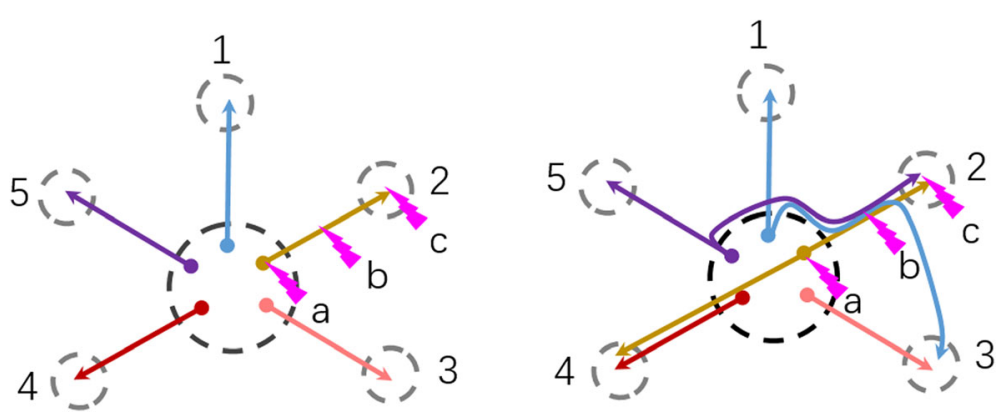

Fig. 5 Schematic of different stimulation sites and activation effects based on different axon projection styles. Left, if projection style is 'one area, one target', there are no different activation effects in projecting to target 2 between the cell body, axon pathway, and axon terminal stimulation. Right, if the projection style is 'one area, multiple targets', there are many different activation effects between the cell body, axon pathway, and axon terminal stimulation. Stimulating the cell body may activate target 2 and 4 , stimulating the axon pathway may activate target 2 and 3, and stimulating the axon terminal may activate target 2 only 
limitations and started to compare effects between two different targets: i.e., the fornix and NBM. Two such prospective double-blind comparison studies will be conducted at Hospital San Carlos, Madrid (ClinicalTrials.gov Identifier: NCT03290274) and Xuanwu Hospital, Beijing (ClinicalTrials.gov Identifier: NCT03352739).

Individual cortical neurons often innervate multiple target regions [118], therefore, the effects could be different when stimulating the axon terminal, axon pathway, or cell body (Fig. 5). A systematic review of the broad literature concerning electrical stimulation concluded that the qualitative nature of electrically evoked memories largely depends on the site of stimulation. Specifically, stimulation in the rhinal cortex usually induces personal semantic reminiscences, whereas hippocampal stimulation induces episodic memories [119]. In animal studies, it is not possible to distinguish semantic reminiscences from episodic memories; however, in light of the anatomical relationship between the EC and hippocampus, we postulate that EC-DBS mainly affects the hippocampus. Additional research is needed to clarify the EC-hippocampus effect and the differences in stimulation patterns between EC-DBS and f-DBS.

Furthermore, electrical DBS that targets a brain area or pathway cannot distinguish cell type and afferent source. Due to optogenetics, however, we can selectively activate a subgroup of cell bodies in one location or their axon terminal in one of their destination locations and compare the effects on target neuron activity or animal behavior. Nevertheless, it is still not clear whether we can directly translate the effects of cell type-specific or target-specific optogenetic DBS into electrical DBS, particularly as recent research indicates that astrocyte activity may also contribute to de novo neuronal potentiation and memory enhancement [120]. Furthermore, optogenetic stimulation in certain instances may not yield clinical benefits due to its high specificity, which can be a clinical disadvantage.

Although many clinical and animal studies of DBS have shed light on this as a possible new therapy for AD, many more studies are required to systematically evaluate the effects of electrical stimulation and its underlying mechanism.

\section{Abbreviations \\ ACh: Acetylcholine; AD: Alzheimer's disease; AB: Amyloid beta; BF: Basal forebrain; DBS: Deep brain stimulation; DG: Dentate gyrus; EC: Entorhinal cortex; f-DBS: fornix-DBS; HDB: Horizontal limb of diagonal band; LEC: Lateral EC; MB: Mammillary body; MEC: Medial EC; NBM: Nucleus basalis of Meynert; PET: Positron emission tomography; VDB: Vertical limb of diagonal band}

\section{Acknowledgements}

Not applicable.

\section{Authors' contributions}

DFY, HHY: equally contributed to literature search, writing, and editing of the manuscript; JZ, XDY: read and commented on the final version of the manuscript; YML, YYH: supervised the literature search, discussion, and writing of the manuscript. All authors read and approved the final manuscript.

\section{Funding}

This work was supported financially by the National Natural Science Foundation of China (No. 81603095 to Dr. Danfang Yu, No. 31600847 and No. 31871089 to Dr. Yunyun Han) and China Postdoctoral Science

Foundation (No. 2018 M632873 to Dr. Danfang Yu).

\section{Availability of data and materials}

Not applicable.

Ethics approval and consent to participate

Not applicable.

Consent for publication

Not applicable.

\section{Competing interests}

The authors declare that they have no competing interests.

\section{Author details}

${ }^{1}$ Department of Neurobiology, School of Basic Medicine and Tongji Medical College, Huazhong University of Science and Technology, Wuhan, China. ${ }^{2}$ Department of Neurology, Provincial Hospital of Integrated Chinese \& Western Medicine, Wuhan, China. ${ }^{3}$ Department of Physiology, School of Basic Medicine and Tongji Medical College, Huazhong University of Science and Technology, Wuhan, China. ${ }^{4}$ Institute for Brain Research, Collaborative Innovation Center for Brain Science, Huazhong University of Science and Technology, Wuhan, China. ${ }^{5}$ Biomedical Engineering Department, Huazhong University of Science and Technology, Wuhan, China.

Received: 26 February 2019 Accepted: 26 July 2019

Published online: 08 August 2019

\section{References}

1. Hickman RA, Faustin A, Wisniewski T. Alzheimer disease and its growing epidemic: risk factors, biomarkers, and the urgent need for therapeutics. Neurol Clin. 2016;34:941-53.

2. Morris GP, Clark IA, Vissel B. Inconsistencies and controversies surrounding the amyloid hypothesis of Alzheimer's disease. Acta Neuropathol Commun. 2014;2:135.

3. Assoc A. Alzheimer's Association Report 2015 Alzheimer's disease facts and figures. Alzheimers Dement. 2015;11:332-84.

4. Corbett A, Smith J, Ballard C. New and emerging treatments for Alzheimer's disease. Expert Rev Neurother. 2012;12:535-43.

5. Viana JNM, Vickers JC, Cook MJ, Gilbert F. Currents of memory: recent progress, translational challenges, and ethical considerations in fornix deep brain stimulation trials for Alzheimer's disease. Neurobiol Aging. 2017;56: 202-10.

6. Sharma A, Szeto K, Desilets AR. Efficacy and safety of deep brain stimulation as an adjunct to pharmacotherapy for the treatment of Parkinson disease. Ann Pharmacother. 2012:46:248-54.

7. Holslag JAH, Neef N, Beudel M, Drost G, Oterdoom DLM, Kremer NI, van Laar T, van Dijk JMC. Deep brain stimulation for essential tremor: a comparison of targets. World Neurosurg. 2018;110:e580-e584.

8. Ruvalcaba Y. Effectiveness of bilateral deep-brain stimulation on dystonia: response to the latest meta-analysis. Eur J Neurol. 2017;24:e35.

9. Zhou C, Zhang H, Qin Y, Tian T, Xu B, Chen J, Zhou X, Zeng L, Fang L, Qi X, et al. A systematic review and meta-analysis of deep brain stimulation in treatment-resistant depression. Prog Neuropsychopharmacol Biol Psychiatry. 2018:82:224-232.

10. Vazquez-Bourgon J, Martino J, Sierra Pena M, Infante Ceberio J, Martinez Martinez MA, Ocon R, Menchon JM, Crespo Facorro B, Vazquez-Barquero A. Deep brain stimulation and treatment-resistant obsessive-compulsive disorder: a systematic review. Rev Psiquiatr Salud Ment. 2019;12:37-51.

11. Baldermann JC, Schuller T, Huys D, Becker I, Timmermann L, Jessen F, VisserVandewalle $V$, Kuhn J. Deep brain stimulation for Tourette-syndrome: a systematic review and meta-analysis. Brain Stimul. 2016;9:296-304. 
12. Nangunoori RK, Tomycz ND, Oh MY, Whiting DM. Deep brain stimulation for obesity: from a theoretical framework to practical application. Neural Plast. 2016;2016:7971460.

13. Hollingworth M, Sims-Williams HP, Pickering AE, Barua N, Patel NK. Single Electrode Deep Brain Stimulation with Dual Targeting at Dual Frequency for the Treatment of Chronic Pain: A Case Series and Review of the Literature. Brain Sci. 2017;7. https://doi.org/10.3390/brainsci7010009.

14. Hamani C, McAndrews MP, Cohn M, Oh M, Zumsteg D, Shapiro CM, Wennberg RA, Lozano AM. Memory enhancement induced by hypothalamic/fornix deep brain stimulation. Ann Neurol. 2008;63:119-23.

15. Freund HJ, Kuhn J, Lenartz D, Mai JK, Schnell T, Klosterkoetter J, Sturm V. Cognitive functions in a patient with Parkinson-dementia syndrome undergoing deep brain stimulation. Arch Neurol. 2009;66:781-5.

16. Xia F, Yiu A, Stone SSD, Oh S, Lozano AM, Josselyn SA, Frankland PW. Entorhinal cortical deep brain stimulation rescues memory deficits in both young and old mice genetically engineered to model Alzheimer's disease. Neuropsychopharmacology. 2017:42:2493-503.

17. Baldermann JC, Hardenacke K, Hu X, Koster P, Horn A, Freund HJ, Zilles K, Sturm $V$, Visser-Vandewalle $V$, Jessen $F$, et al. Neuroanatomical characteristics associated with response to deep brain stimulation of the nucleus basalis of Meynert for Alzheimer's disease. Neuromodulation. 2018;21:184-90.

18. Zhu H, Yan H, Tang N, Li X, Pang P, Li H, Chen W, Guo Y, Shu S, Cai Y, et al. Impairments of spatial memory in an Alzheimer's disease model via degeneration of hippocampal cholinergic synapses. Nat Commun. 2017:8:1676.

19. Scharre DW, Weichart E, Nielson D, Zhang J, Agrawal P, Sederberg PB, Knopp MV, Rezai AR, Alzheimer's disease neuroimaging I. Deep brain stimulation of frontal lobe networks to treat Alzheimer's disease. J Alzheimers Dis. 2018;62:621-33.

20. McKhann GM, Knopman DS, Chertkow H, Hyman BT, Jack CR Jr, Kawas CH, Klunk WE, Koroshetz WJ, Manly JJ, Mayeux R, et al. The diagnosis of dementia due to Alzheimer's disease: recommendations from the National Institute on Aging-Alzheimer's Association workgroups on diagnostic guidelines for Alzheimer's disease. Alzheimers Dement. 2011;7:263-9.

21. Andersen P, Morris R, Amaral D, Bliss TVP. \& O'keefe J. The HippocampusBook. New York: Oxford University Press Inc.

22. Schroder J, Pantel J. Neuroimaging of hippocampal atrophy in early recognition of Alzheimer's disease--a critical appraisal after two decades of research. Psychiatry Res. 2016;247:71-8.

23. Braak H, Braak E. Neuropathological stageing of Alzheimer-related changes. Acta Neuropathol. 1991;82:239-59.

24. Johnson KA, Schultz A, Betensky RA, Becker JA, Sepulcre J, Rentz D, Mormino E, Chhatwal J, Amariglio R, Papp K, et al. Tau positron emission tomographic imaging in aging and early Alzheimer disease. Ann Neurol. 2016;79:110-9

25. Browning PG, Gaffan D, Croxson PL, Baxter MG. Severe scene learning impairment, but intact recognition memory, after cholinergic depletion of inferotemporal cortex followed by fornix transection. Cereb Cortex. 2010;20: 282-93.

26. Mugikura S, Takahashi S. Infarction in the pars libera of the column of fornix including pre (cholinergic)- and post (circuit of Papez fiber tracts)commissural fibers causes "basal forebrain" amnesia. Neuroradiology. 2015; 57:757-9.

27. Zahr NM, Rohlfing T, Pfefferbaum A, Sullivan EV. Problem solving, working memory, and motor correlates of association and commissural fiber bundles in normal aging: a quantitative fiber tracking study. Neuroimage. 2009;44: 1050-62.

28. Copenhaver BR, Rabin LA, Saykin AJ, Roth RM, Wishart HA, Flashman LA, Santulli RB, McHugh TL, Mamourian AC. The fornix and mammillary bodies in older adults with Alzheimer's disease, mild cognitive impairment, and cognitive complaints: a volumetric MRI study. Psychiatry Res. 2006;147:93-103.

29. Ringman JM, O'Neill J, Geschwind D, Medina L, Apostolova LG, Rodriguez Y, Schaffer B, Varpetian A, Tseng B, Ortiz F, et al. Diffusion tensor imaging in preclinical and presymptomatic carriers of familial Alzheimer's disease mutations. Brain. 2007;130:1767-76.

30. Bartus RT, Dean RL 3rd, Beer B, Lippa AS. The cholinergic hypothesis of geriatric memory dysfunction. Science. 1982;217:408-14.

31. Whitehouse PJ, Price DL, Clark AW, Coyle JT, DeLong MR. Alzheimer disease: evidence for selective loss of cholinergic neurons in the nucleus basalis. Ann Neurol. 1981;10:122-6.
32. Mesulam M, Shaw P, Mash D, Weintraub S. Cholinergic nucleus basalis tauopathy emerges early in the aging-MCl-AD continuum. Ann Neurol. 2004;55:815-28.

33. Baker-Nigh A, Vahedi S, Davis EG, Weintraub S, Bigio EH, Klein WL, Geula C. Neuronal amyloid-beta accumulation within cholinergic basal forebrain in ageing and Alzheimer's disease. Brain. 2015;138:1722-37.

34. Yan H, Pang P, Chen W, Zhu H, Henok KA, Li H, Wu Z, Ke X, Wu J, Zhang T, et al. The lesion analysis of cholinergic neurons in 5XFAD mouse model in the three-dimensional level of whole brain. Mol Neurobiol. 2018;55:41154125 .

35. Whitehouse PJ, Price DL, Struble RG, Clark AW, Coyle JT, Delon MR. Alzheimer's disease and senile dementia: loss of neurons in the basal forebrain. Science. 1982;215:1237-9.

36. Vogels OJ, Renkawek K, Broere CA, ter Laak HJ, van Workum F. Galanin-like immunoreactivity within Ch2 neurons in the vertical limb of the diagonal band of Broca in aging and Alzheimer's disease. Acta Neuropathol. 1989;78: 90-5.

37. Fogwe LA, Mesfin FB. Neuroanatomy, Hippocampus. [Updated 2019 Feb 28]. In: StatPearls [Internet]. Treasure Island (FL): StatPearlsPublishing; 2019 Jan. Available from: https://www.ncbi.nlm.nih.gov/books/NBK482171/.

38. Witter MP, Doan TP, Jacobsen B, Nilssen ES, Ohara S. Architecture of the entorhinal cortex a review of entorhinal anatomy in rodents with some comparative notes. Front Syst Neurosci. 2017;11:46.

39. Hafting T, Fyhn M, Molden S, Moser MB, Moser El. Microstructure of a spatial map in the entorhinal cortex. Nature. 2005:436:801-6.

40. Hargreaves EL, Rao G, Lee I, Knierim JJ. Major dissociation between medial and lateral entorhinal input to dorsal hippocampus. Science. 2005;308:1792-4.

41. Deshmukh SS, Knierim JJ. Representation of non-spatial and spatial information in the lateral entorhinal cortex. Front Behav Neurosci. 2011;5:69.

42. van Strien NM, Cappaert NL, Witter MP. The anatomy of memory: an interactive overview of the parahippocampal-hippocampal network. Nat Rev Neurosci. 2009:10:272-82.

43. Burwell RD. The parahippocampal region: corticocortical connectivity. Ann N Y Acad Sci. 2000;911:25-42.

44. Li Y, Xu J, Liu Y, Zhu J, Liu N, Zeng W, Huang N, Rasch MJ, Jiang H, Gu X, et al. A distinct entorhinal cortex to hippocampal CA1 direct circuit for olfactory associative learning. Nat Neurosci. 2017;20:559-70.

45. Thomas AG, Koumellis $P$, Dineen RA. The fornix in health and disease: an imaging review. Radiographics. 2011;31:1107-21.

46. Vann SD, Nelson AJ. The mammillary bodies and memory: more than a hippocampal relay. Prog Brain Res. 2015;219:163-85.

47. Yamada K, Shrier DA, Rubio A, Yoshiura T, Iwanaga S, Shibata DK, Patel U, Numaguchi Y. MR imaging of the mamillothalamic tract. Radiology. 1998; 207:593-8.

48. Ballinger EC, Ananth M, Talmage DA, Role LW. Basal forebrain cholinergic circuits and signaling in cognition and cognitive decline. Neuron. 2016;91: 1199-218.

49. Li X, Yu B, Sun Q, Zhang Y, Ren M, Zhang X, Li A, Yuan J, Madisen L, Luo Q, et al. Generation of a whole-brain atlas for the cholinergic system and mesoscopic projectome analysis of basal forebrain cholinergic neurons. Proc Natl Acad Sci U S A. 2018:115:415-20.

50. Gorry JD. Studies on the comparative anatomy of the ganglion Basale of Meynert. Acta Anat (Basel). 1963:55:51-104.

51. Mesulam MM, Geula C. Nucleus basalis (Ch4) and cortical cholinergic innervation in the human brain: observations based on the distribution of acetylcholinesterase and choline acetyltransferase. J Comp Neurol. 1988;275: 216-40.

52. Mesulam MM, Mufson EJ, Levey Al, Wainer BH. Cholinergic innervation of cortex by the basal forebrain: cytochemistry and cortical connections of the septal area, diagonal band nuclei, nucleus basalis (substantia innominata), and hypothalamus in the rhesus monkey. J Comp Neurol. 1983;214:170-97.

53. Woolf NJ. Cholinergic systems in mammalian brain and spinal cord. Prog Neurobiol. 1991;37:475-524.

54. Mesulam MM, Mufson EJ, Levey Al, Wainer BH. Atlas of cholinergic neurons in the forebrain and upper brainstem of the macaque based on monoclonal choline acetyltransferase immunohistochemistry and acetylcholinesterase histochemistry. Neuroscience. 1984;12:669-86.

55. Nyakas C, Luiten PG, Spencer DG, Traber J. Detailed projection patterns of septal and diagonal band efferents to the hippocampus in the rat with emphasis on innervation of CA1 and dentate gyrus. Brain Res Bull. 1987;18: 533-45. 
56. Peterson GM. Differential projections to the hippocampus by neurons of the medial septum and vertical limb of the diagonal band. Brain Res. 1994 646:129-34.

57. Zheng $Y$, Feng $S$, Zhu X, Jiang W, Wen $P$, Ye F, Rao X, Jin S, He X, Xu F. Different subgroups of cholinergic neurons in the basal forebrain are distinctly innervated by the olfactory regions and activated differentially in olfactory memory retrieval. Front Neural Circuits. 2018;12:99.

58. Mesulam MM, Mufson EJ. Neural inputs into the nucleus basalis of the substantia innominata (Ch4) in the rhesus monkey. Brain. 1984;107(Pt 1): 253-74.

59. Smiley JF, Mesulam MM. Cholinergic neurons of the nucleus basalis of Meynert receive cholinergic, catecholaminergic and GABAergic synapses: an electron microscopic investigation in the monkey. Neuroscience. 1999;88: 241-55

60. Mirzadeh Z, Bari A, Lozano AM. The rationale for deep brain stimulation in Alzheimer's disease. J Neural Transm (Vienna). 2016;123:775-83.

61. Laxton AW, Tang-Wai DF, McAndrews MP, Zumsteg D, Wennberg R, Keren R, Wherrett J, Naglie G, Hamani C, Smith GS, Lozano AM. A phase I trial of deep brain stimulation of memory circuits in Alzheimer's disease. Ann Neurol. 2010;68:521-34.

62. Smith GS, Laxton AW, Tang-Wai DF, McAndrews MP, Diaconescu AO, Workman Cl, Lozano AM. Increased cerebral metabolism after 1 year of deep brain stimulation in Alzheimer disease. Arch Neurol. 2012;69:1141-8.

63. Sankar T, Chakravarty MM, Bescos A, Lara M, Obuchi T, Laxton AW, McAndrews MP, Tang-Wai DF, Workman Cl, Smith GS, Lozano AM. Deep brain stimulation influences brain structure in Alzheimer's disease. Brain Stimul. 2015;8:645-54.

64. Holroyd KB, Fosdick L, Smith GS, Leoutsakos JM, Munro CA, Oh ES, Drake KE, Rosenberg PB, Anderson WS, Salloway S, et al. Deep brain stimulation targeting the fornix for mild Alzheimer dementia: design of the ADvance randomized controlled trial. Open Access J Clin T. 2015;7:63-76.

65. Lozano AM, Fosdick L, Chakravarty MM, Leoutsakos JM, Munro C, Oh E, Drake KE, Lyman CH, Rosenberg PB, Anderson WS, et al. A phase II study of fornix deep brain stimulation in mild Alzheimer's disease. J Alzheimers Dis. 2016;54:777-87.

66. Penfield W. Some mechanisms of consciousness discovered during electrical stimulation of the brain. Proc Natl Acad Sci U S A. 1958;44:51-66.

67. Suthana N, Haneef Z, Stern J, Mukamel R, Behnke E, Knowlton B, Fried I. Memory enhancement and deep-brain stimulation of the entorhinal area. $N$ Engl J Med. 2012;366:502-10.

68. Stone SS, Teixeira CM, Devito LM, Zaslavsky K, Josselyn SA, Lozano AM, Frankland PW. Stimulation of entorhinal cortex promotes adult neurogenesis and facilitates spatial memory. J Neurosci. 2011;31:13469-84.

69. Turnbull IM, McGeer PL, Beattie L, Calne D, Pate B. Stimulation of the basal nucleus of Meynert in senile dementia of Alzheimer's type. A preliminary report. Appl Neurophysiol. 1985;48:216-21.

70. Kuhn J, Hardenacke K, Lenartz D, Gruendler T, Ullsperger M, Bartsch C, Mai JK, Zilles K, Bauer A, Matusch A, et al. Deep brain stimulation of the nucleus basalis of Meynert in Alzheimer's dementia. Mol Psychiatry. 2015;20:353-60.

71. Kuhn J, Hardenacke K, Shubina E, Lenartz D, Visser-Vandewalle V, Zilles K, Sturm V, Freund HJ. Deep brain stimulation of the nucleus basalis of Meynert in early stage of Alzheimer's dementia. Brain Stimul. 2015;8:838-9.

72. Noreik M, Kuhn J, Hardenacke K, Lenartz D, Bauer A, Buhrle CP, Haussermann P, Hellmich M, Klosterkotter J, Wiltfang J, et al. Changes in nutritional status after deep brain stimulation of the nucleus basalis of Meynert in Alzheimer's disease--results of a phase I study. J Nutr Health Aging. 2015;19:812-8.

73. Hardenacke K, Hashemiyoon R, Visser-Vandewalle V, Zapf A, Freund HJ, Sturm V, Hellmich M, Kuhn J. Deep brain stimulation of the nucleus basalis of Meynert in Alzheimer's dementia: potential predictors of cognitive change and results of a long-term follow-up in eight patients. Brain Stimul. 2016:9:799-800.

74. Vann SD, Erichsen JT, O'Mara SM, Aggleton JP. Selective disconnection of the hippocampal formation projections to the mammillary bodies produces only mild deficits on spatial memory tasks: implications for fornix function. Hippocampus. 2011:21:945-57.

75. Vann SD. Dismantling the Papez circuit for memory in rats. Elife. 2013;2: e00736.

76. Yang X, Yao C, Tian T, Li X, Yan H, Wu J, Li H, Pei L, Liu D, Tian Q, et al. A novel mechanism of memory loss in Alzheimer's disease mice via the degeneration of entorhinal-CA1 synapses. Mol Psychiatry. 2018;23:199-210.
77. Roy DS, Arons A, Mitchell TI, Pignatelli M, Ryan TJ, Tonegawa S. Memory retrieval by activating engram cells in mouse models of early Alzheimer's disease. Nature. 2016:531:508-12.

78. Deng W, Aimone JB, Gage FH. New neurons and new memories: how does adult hippocampal neurogenesis affect learning and memory? Nat Rev Neurosci. 2010;11:339-50.

79. Kotani S, Yamauchi T, Teramoto T, Ogura H. Pharmacological evidence of cholinergic involvement in adult hippocampal neurogenesis in rats. Neuroscience. 2006;142:505-14.

80. Cooper-Kuhn CM, Winkler J, Kuhn HG. Decreased neurogenesis after cholinergic forebrain lesion in the adult rat. J Neurosci Res. 2004;77:155-65.

81. Hescham S, Temel Y, Schipper S, Lagiere M, Schonfeld LM, Blokland A, Jahanshahi A. Fornix deep brain stimulation induced long-term spatial memory independent of hippocampal neurogenesis. Brain Struct Funct. 2017:222:1069-75.

82. Sokoloff L. Localization of functional activity in the central nervous system by measurement of glucose utilization with radioactive deoxyglucose. J Cereb Blood Flow Metab. 1981;1:7-36.

83. Smith GS, de Leon MJ, George AE, Kluger A, Volkow ND, McRae T, Golomb J, Ferris SH, Reisberg B, Ciaravino J, et al. Topography of cross-sectional and longitudinal glucose metabolic deficits in Alzheimer's disease. Pathophysiologic implications. Arch Neurol. 1992;49:1142-50.

84. Minoshima S, Giordani B, Berent S, Frey KA, Foster NL, Kuhl DE. Metabolic reduction in the posterior cingulate cortex in very early Alzheimer's disease. Ann Neurol. 1997;42:85-94.

85. Patel AB, Lai JC, Chowdhury GM, Hyder F, Rothman DL, Shulman RG, Behar $\mathrm{KL}$. Direct evidence for activity-dependent glucose phosphorylation in neurons with implications for the astrocyte-to-neuron lactate shuttle. Proc Natl Acad Sci U S A. 2014;111:5385-90.

86. Pellerin L, Magistretti PJ. Sweet sixteen for ANLS. J Cereb Blood Flow Metab. 2012;32:1152-66.

87. Tang BL. Brain activity-induced neuronal glucose uptake/glycolysis: is the lactate shuttle not required? Brain Res Bull. 2018;137:225-8.

88. Fox PT, Raichle ME, Mintun MA, Dence C. Nonoxidative glucose consumption during focal physiologic neural activity. Science. 1988;241: 462-4.

89. Kwong KK, Belliveau JW, Chesler DA, Goldberg IE, Weisskoff RM, Poncelet BP, Kennedy DN, Hoppel BE, Cohen MS, Turner R, et al. Dynamic magnetic resonance imaging of human brain activity during primary sensory stimulation. Proc Natl Acad Sci U S A. 1992;89:5675-9.

90. Min HK, Hwang SC, Marsh MP, Kim I, Knight E, Striemer B, Felmlee JP, Welker KM, Blaha CD, Chang SY, et al. Deep brain stimulation induces BOLD activation in motor and non-motor networks: an fMRI comparison study of STN and EN/GPi DBS in large animals. Neuroimage. 2012;63:1408-20.

91. Chao TH, Chen JH, Yen CT. Repeated BOLD-fMRI imaging of deep brain stimulation responses in rats. PLoS One. 2014:9:e97305.

92. Angenstein F, Krautwald K, Wetzel W, Scheich H. Perforant pathway stimulation as a conditioned stimulus for active avoidance learning triggers BOLD responses in various target regions of the hippocampus: a combined fMRI and electrophysiological study. Neuroimage. 2013;75: 213-27

93. Helbing C, Brocka M, Scherf T, Lippert MT, Angenstein F. The role of the mesolimbic dopamine system in the formation of blood-oxygen-level dependent responses in the medial prefrontal/anterior cingulate cortex during high-frequency stimulation of the rat perforant pathway. J Cereb Blood Flow Metab. 2016:36:2177-93.

94. Hescham S, Jahanshahi A, Schweimer JV, Mitchell SN, Carter G, Blokland A Sharp T, Temel Y. Fornix deep brain stimulation enhances acetylcholine levels in the hippocampus. Brain Struct Funct. 2016;221:4281-6.

95. Votaw $\mathrm{CL}$, Lauer EW. An afferent hippocampal Fiber system in the fornix of the monkey. J Comp Neurol. 1963;121:195-206.

96. Buzsaki G, Bickford RG, Ponomareff G, Thal LJ, Mandel R, Gage FH. Nucleus basalis and thalamic control of neocortical activity in the freely moving rat. J Neurosci. 1988:8:4007-26.

97. Kurosawa M, Sato A, Sato Y. Stimulation of the nucleus basalis of Meynert increases acetylcholine release in the cerebral cortex in rats. Neurosci Lett. 1989:98:45-50.

98. Liu R, Crawford J, Callahan PM, Terry AV Jr, Constantinidis C, Blake DT. Intermittent stimulation of the nucleus basalis of Meynert improves working memory in adult monkeys. Curr Biol. 2017;27:2640-6 e2644. 
99. Ross EK, Kim JP, Settell ML, Han SR, Blaha CD, Min HK, Lee KH. Fornix deep brain stimulation circuit effect is dependent on major excitatory transmission via the nucleus accumbens. Neuroimage. 2016;128:138-48.

100. Roy DS, Kitamura T, Okuyama T, Ogawa SK, Sun C, Obata Y, Yoshiki A, Tonegawa S. Distinct neural circuits for the formation and retrieval of episodic memories. Cell. 2017;170:1000-12 e1019.

101. Nobili A, Latagliata EC, Viscomi MT, Cavallucci V, Cutuli D, Giacovazzo G, Krashia P, Rizzo FR, Marino R, Federici M, et al. Dopamine neuronal loss contributes to memory and reward dysfunction in a model of Alzheimer's disease. Nat Commun. 2017;8:14727.

102. Perez SM, Lodge DJ. Convergent inputs from the hippocampus and thalamus to the nucleus accumbens regulate dopamine neuron activity. J Neurosci. 2018;38:10607-10618.

103. Parsons TD, Rogers SA, Braaten AJ, Woods SP, Troster Al. Cognitive sequelae of subthalamic nucleus deep brain stimulation in Parkinson's disease: a meta-analysis. Lancet Neurol. 2006;5:578-88.

104. Jacobsen JS, Wu CC, Redwine JM, Comery TA, Arias R, Bowlby M, Martone R, Morrison JH, Pangalos MN, Reinhart PH, Bloom FE. Early-onset behavioral and synaptic deficits in a mouse model of Alzheimer's disease. Proc Natl Acad Sci U S A. 2006;103:5161-6.

105. Hsia AY, Masliah E, McConlogue L, Yu GQ, Tatsuno G, Hu K, Kholodenko D, Malenka RC, Nicoll RA, Mucke L. Plaque-independent disruption of neural circuits in Alzheimer's disease mouse models. Proc Natl Acad Sci U S A. 1999;96:3228-33.

106. Mucke L, Masliah E, Yu GQ, Mallory M, Rockenstein EM, Tatsuno G, Hu K Kholodenko D, Johnson-Wood K, McConlogue L. High-level neuronal expression of abeta 1-42 in wild-type human amyloid protein precursor transgenic mice: synaptotoxicity without plaque formation. J Neurosci. 2000; 20:4050-8.

107. Panza F, Seripa D, Solfrizzi V, Imbimbo BP, Lozupone M, Leo A, Sardone R, Gagliardi G, Lofano L, Creanza BC, et al. Emerging drugs to reduce abnormal beta-amyloid protein in Alzheimer's disease patients. Expert Opin Emerg Drugs. 2016;21:377-91.

108. Dodart JC, Bales KR, Gannon KS, Greene SJ, DeMattos RB, Mathis C, DeLong CA, Wu S, Wu X, Holtzman DM, Paul SM. Immunization reverses memory deficits without reducing brain Abeta burden in Alzheimer's disease model. Nat Neurosci. 2002;5:452-7.

109. Tricco AC, Ashoor HM, Soobiah C, Rios P, Veroniki AA, Hamid JS, Ivory JD, Khan PA, Yazdi F, Ghassemi M, et al. Comparative effectiveness and safety of cognitive enhancers for treating Alzheimer's disease: systematic review and network Metaanalysis. J Am Geriatr Soc. 2018;66:170-178.

110. Lebois EP, Thorn C, Edgerton JR, Popiolek M, Xi S. Muscarinic receptor subtype distribution in the central nervous system and relevance to aging and Alzheimer's disease. Neuropharmacology. 2018;136:362-373.

111. Levey Al, Edmunds SM, Koliatsos V, Wiley RG, Heilman CJ. Expression of m1m4 muscarinic acetylcholine receptor proteins in rat hippocampus and regulation by cholinergic innervation. J Neurosci. 1995;15:4077-92.

112. Levey Al, Kitt CA, Simonds WF, Price DL, Brann MR. Identification and localization of muscarinic acetylcholine receptor proteins in brain with subtype-specific antibodies. J Neurosci. 1991;11:3218-26.

113. Lindsley C, Lewis M, Weaver D. Discovery of a Highly Selective in vitro and in vivo M1 Allosteric Agonist Probe. 2008 Dec 3 [Updated 2010 Oct 4]. In: Probe Reports from the NIH Molecular Libraries Program [Internet]. Bethesda (MD): National Center for Biotechnology Information (US); 2010. Available from: https://www.ncbi.nlm.nih.gov/books/NBK47340/.

114. Melancon BJ, Tarr JC, Panarese JD, Wood MR, Lindsley CW. Allosteric modulation of the M1 muscarinic acetylcholine receptor: improving cognition and a potential treatment for schizophrenia and Alzheimer's disease. Drug Discov Today. 2013;18:1185-99.

115. Johnson MD, Miocinovic S, Mclntyre CC, Vitek JL. Mechanisms and targets of deep brain stimulation in movement disorders. Neurotherapeutics. 2008;5:294-308.

116. Kitamura T, Ogawa SK, Roy DS, Okuyama T, Morrissey MD, Smith LM, Redondo RL, Tonegawa S. Engrams and circuits crucial for systems consolidation of a memory. Science. 2017;356:73-8.

117. Hangya B, Ranade SP, Lorenc M, Kepecs A. Central cholinergic neurons are rapidly recruited by reinforcement feedback. Cell. 2015;162:1155-68.

118. Han YY, Kebschull JM, Campbell RAA, Cowan D, Imhof F, Zador AM, MrsicFlogel TD. The logic of single-cell projections from visual cortex. Nature. 2018;556:51.

119. Curot J, Busigny T, Valton L, Denuelle M, Vignal JP, Maillard L, Chauvel $P$, Pariente J, Trebuchon A, Bartolomei F, Barbeau EJ. Memory scrutinized through electrical brain stimulation: a review of 80 years of experiential phenomena. Neurosci Biobehav Rev. 2017;78:161-77.

120. Adamsky A, Kol A, Kreisel T, Doron A, Ozeri-Engelhard N, Melcer T, Refaeli R, Horn H, Regev L, Groysman M, et al. Astrocytic activation generates De novo neuronal potentiation and memory enhancement. Cell. 2018;174:5971 e14.

\section{Publisher's Note}

Springer Nature remains neutral with regard to jurisdictional claims in published maps and institutional affiliations.
Ready to submit your research? Choose BMC and benefit from:

- fast, convenient online submission

- thorough peer review by experienced researchers in your field

- rapid publication on acceptance

- support for research data, including large and complex data types

- gold Open Access which fosters wider collaboration and increased citations

- maximum visibility for your research: over $100 \mathrm{M}$ website views per year

At BMC, research is always in progress.

Learn more biomedcentral.com/submissions 